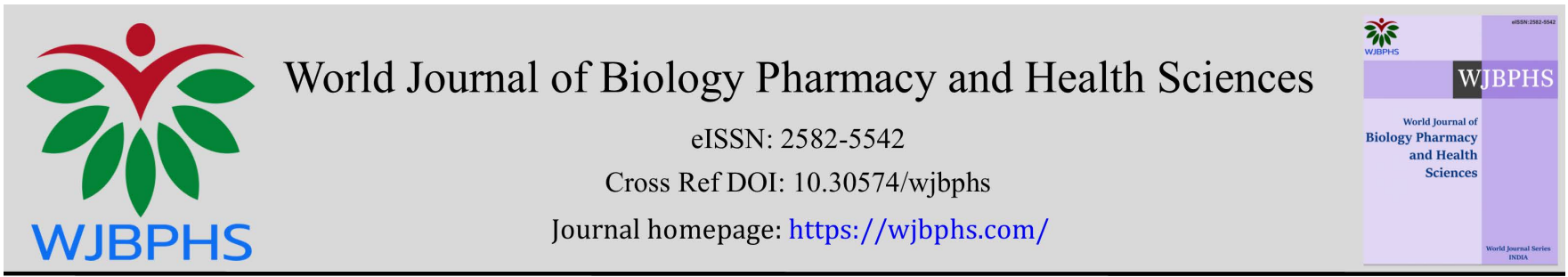

(RESEARCH ARTiCLE)

\title{
A rare anatomical variation in foramen of Vesalius: A useful guide for maxillofacial surgeons
}

\section{G. Priya *}

\section{Department of Anatomy, Panimalar Medical College Hospital \& Research Institute, Varadharajapuram, Chennai Outer} Ring Road, Poonamallee, Chennai, Tamilnadu-600123, India

World Journal of Biology Pharmacy and Health Sciences, 2022, 09(01), 001-004

Publication history: Received on 25 November 2021; revised on 05 January 2022; accepted on 07 January 2022

Article DOI: https://doi.org/10.30574/wjbphs.2022.9.1.0130

\begin{abstract}
Background: Foramen of vesalius is an inconstant foramen that gives passage to an emissary vein that connects pterygoid venous plexus with cavernous sinus. It lies in the anteromedial side of the foramen ovale. Foramen ovale allows the passage for the mandibular branch of trigeminal nerve, the main site for the trigeminal rhizotomy. The presence and description of anatomical variations about the foramen of Vesalius is important during the surgical procedure on the trigeminal nerve which may injure the emissary vein in the foramen leading to intracranial bleeding.
\end{abstract}

Objectives: The aim of the present study is to report the presence and to enlighten the anatomical variations of foramen vesalius which may serve as a guideline for surgeons.

Methods: The study was conducted on 100 dry adult human skulls collected from the department of anatomy at Panimalar medical college hospital \& research institute Chennai. The skulls were viewed both extracranially and intracranially to identify the presence of foramen of vesalius. The presence and variation of the foramen was noted and discussed.

Result: A total of about 200 sides of 100 skulls were studied. Among them $20 \%$ of the skull showed presence of foramen of Vesalius bilaterally, 25\% unilaterally and one particular skull showed doubled opening on the left side with the presence of a bony septum. This is a rare variation which was less documented in the literature.

Conclusion: The knowledge of variations in foramen of Vesalius may help the surgeons for safer planning and execution of the trigeminal rhizotomy technique.

Keywords: Anatomical variation; Bony septum; Double foramen of Vesalius; Human Skull; Emissary vein

\section{Introduction}

Foramen of vesalius or sphenoidal emissary foramen is a small foramen found between the foramen ovale and scaphoid fossa. It contains an emissary vein -"vein of vesalius" which links the pterygoid venous plexus in the infratemporal fossa with the cavernous sinus in the middle cranial fossa [1].

The intracranial view of the greater wing of sphenoid bone show three foramens namely foramen rotundum, foramen ovale and foramen spinosum. The foramen rotundum is situated just below and behind the medial end of the superior orbital fissure which transmits maxillary nerve. Behind the foramen rotundum is the foramen ovale which transmits

\footnotetext{
* Corresponding author: G. Priya; E-mail: priyagunalan2006@yahoo.co.in

Department of Anatomy, Panimalar Medical College Hospital \& Research Institute, Varadharajapuram, Chennai Outer Ring Road, Poonamallee, Chennai, Tamilnadu-600123, India 
the mandibular nerve. The foramen spinosum is posterolateral to the foramen ovale and transmits the middle meningeal artery $[2,3]$.

The foramen of vesalius if present will be seen between the foramen rotundum and foramen ovale which is the site normally used by the surgeons for treating trigeminal neuralgia. The present study is to report the presence and to enlighten the anatomical variations of foramen of vesalius which may serve as a guideline for surgeons.

\section{Material and methods}

The study was conducted on 100 dry adult human skulls collected from the department of anatomy at Panimalar medical college hospital \& research institute. The skulls were viewed both extracranially and intracranially to identify the presence of foramen of vesalius. The patency of the foramen was confirmed by inserting a needle through the foramen. The presence and variation of the foramen was noted.

\section{Observation}

A total of about 200 sides of 100 skulls were studied. Among them $20 \%$ of the skull showed presence of foramen of vesalius bilaterally, $25 \%$ unilaterally, absent in $45 \%$ and one particular skull showed a rare variation in the interior of the foramen on the left side. It showed double opening in the extra cranial view separated by a bony septum and the openings were named as anterior and posterior foramen of Vesalius [Fig.1].

When viewed intracranially two separate foramens were seen one close to foramen ovale and another near the foramen rotundum. A needle is inserted along the anterior foramen of vesalius, which passed through the foramen close to foramen ovale and the posterior foramen of vesalius opened in the foramen near rotundum. A small depression observed close to posterior foramen vesalius which was obscure [Fig.2]. Since this observation was made on the dry skull, the structures passing through it is not known. There may be double vein of Vesalius have passed through these foramens.



Figure 1 Extra cranial view: Double foramen of Vesalius separated by a bony septum (BS); AFV-anterior foramen vesalius, PFV- posterior foramen vesalius, FO- foramen ovale, FS- foramen spinosum 


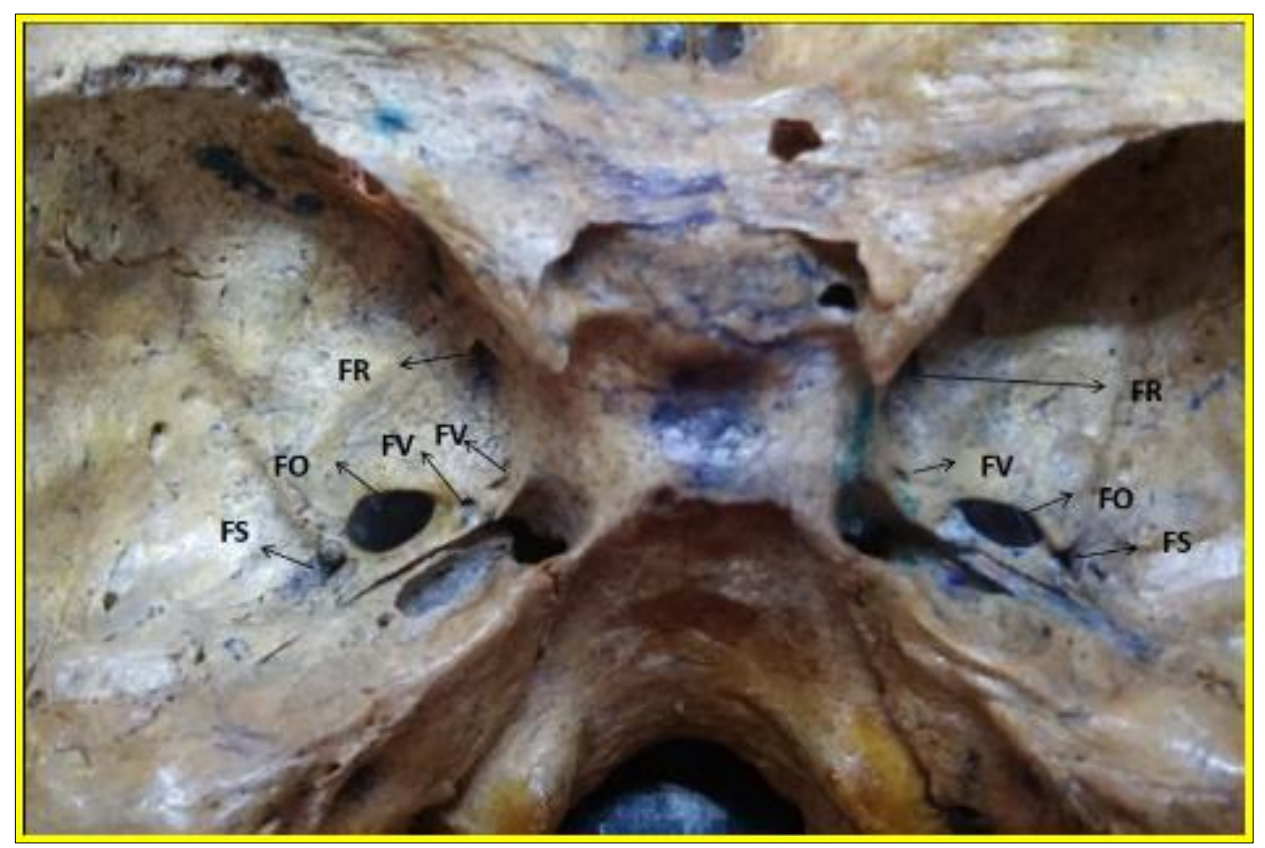

Figure 2 Intra cranial view: Double foramen of Vesalius. FV- foramen Vesalius, FR- foramen rotundum

\section{Discussion}

Foramen of vesalius is a small and inconstant foramen but it is clinically important because an extracranial infection may reach the cavernous sinus through emissary vein transmitted by this foramen, which may lead to cavernous sinus thrombosis. According to gray's anatomy, emissary sphenoidal foramen exists on one or both side in $40 \%$ of the skulls [2]. In the present study foramen of vesalius was found bilaterally in $20 \%$ and unilaterally in $25 \%$ of the skull which was similar to the findings of Murlimanju BV et al [4].

Vesalius in his study mentioned that it is a foramen which could be rarely seen in one side of the skull, and much rarer on both sides [5]. The present study also corroborates with the findings of Wysocki et al who reported presence of this foramen bilaterally in $17 \%$ cases and unilaterally in $13 \%$ cases [6]. According to a study conducted in Japanese population, $21.75 \%$ had foramen Vesalius, bilateral in $75.36 \%$ males, $72.22 \%$ females and unilateral in $24.64 \%$ males, $27.78 \%$ females [7]. Ginsberg et al reported very high incidence of foramen Vesalius in $71.8 \%$ cases [8].

According to various previous studies the incidence of foramen Vesalius is common either unilateral or bilateral. The present study found a unique variation which was less reported in the literature. The double opening of foramen Vesalius separated by a bony septum on the left side of a skull. The foramens were named accordingly as anterior and posterior foramen Vesalius. In extra cranial view of the skull foramen Vesalius was found above foramen ovale and near scaphoid fossa. It showed a bony septum which divided the foramen into two as anterior and posterior foramens. The anterior foramen opened intracranially into a foramen present close to foramen ovale. The posterior foramen opened into a foramen that lies close to foramen rotundum. Since this variation was found in a dry skull the structure passing through these foramens were not sure. But according to gray's anatomy if foramen Vesalius is present, it contains an emissary vein linking the pterygoid venous plexus in the infratemporal fossa with the cavernous sinus in the middle cranial fossa [2]. Based on this statement there may be double emissary veins which would have passed through these foramens.

Shinorhara et al found double foramen vesalius in 7 out of 400 skulls. They reported surgical importance of foramen Vesalius that it can get injured during the trigeminal nerve block technique performed for the trigeminal neuralgia. In this procedure, the foramen can get injured by a displaced instrument which would lead to intracranial bleeding that can spread infection to cavernous sinus [9]. Shapiro and Robinson reported that on some occasions the foramen ovale may coalesce with the foramen Vesalius and sometimes the anterior portion of the foramen ovale may be considered to be the foramen Vesalius [10]. But in the present study the anterior foramen Vesalius was found anterior to foramen ovale and it was not coalesced. 
Kale et al reported that, only 4 out of 156 skulls with foramen Vesalius exhibited the duplication of the foramen Vesalius. Among the double foramen Vesalius, 3 were observed on the right side and 1 was on the left [11]. In the present study the foramen Vesalius appeared single with a bony septum inside separating it into two in extra cranial view. In intracranial view two separate foramens were found, one close to foramen rotundum and other close to foramen ovale. This was a unique variation which was not yet reported in the literature.

The anatomical variation of foramen vesalius should be noticed by the surgeon since it lies close to the foramen ovale, foramen spinosum, foramen lacerum and carotid canal. In the radiological study, it has been reported that foramen vesalius can be better observed radiologically by using thin sliced horizontal CT images [8]. Oser et al reported that during the intervention procedures, the direction, angle and the position of the instrument will change due to the presence of foramen Vesalius [12].

Therefore surgeons should be aware of the presence and variation of the foramen of vesalius as a possible cause of complications during surgical treatments.

\section{Conclusion}

Being small and invariable foramen, the foramen of vesalius is not routinely in attention during surgery. This study suggests that the knowledge of the occurrence and anatomical variation of the foramen of vesalius may assist the surgeons to perform safer surgery.

\section{Compliance with ethical standards}

\section{Conflict of interest}

No conflict of interest.

\section{References}

[1] Gupta N, Ray B, Ghosh S. Anatomic characteristics of foramen Vesalius. Kathmandu Univ Med J (KUMJ). 2005; 3(2): 155-8.

[2] Standring S. Gray's anatomy. 39th Ed. Spain (SP): Churchill Livingstone. 2005; 460-6.

[3] Reymond J, Charuta A, Wysocki J. The morphology and morphometry of the foramina of the greater wing of the human sphenoid bone. Folia Morphol (Warsz). 2005; 64(3): 188-93.

[4] Murlimanju BV, Reddy GR, Latha VP et al. Foramen of Vesalius: Prevalence, Morphology, Embryological Basis and Clinical Implications. Journal of Surgical Academia. 2005; 5(1): 24-28.

[5] Hast MH, Garrison DH. Vesalius on variability of the human skull: Book I, Chapter V of De humani corporis fabrica. Clin Anat. 2000; 13: 311-20.

[6] Wysocki J, Reymond J, Skarryjskih H et al. The size of selected human skull foramina in relation to skull capacity. Folia Morphol. 2006; 65(4): 301-8.

[7] Kodama K, Inoue K, Nagashima M, et al. Studies on the foramen Vesalius in the Japanese juvenile and adult skulls. Hokkaido igaku zasshi. 1997; 72: 667-74.

[8] Ginsberg LE, Prvett SW, Chen MY, et al. Skull-base foramina of the middle cranial fossa: reassessment of normal variation with high - resolution CT. ANJR AM J Neuro radiol. 1994; 15(2): 283-91.

[9] Shinohara AL, De souza melo CG, Silveira EM et al. Incidence, morphology and morphometry of the foramen of Vesalius: complementary study for a safer planning and execution of the trigeminal rhizotomy technique. Surg Radiol Anat. 2010; 32(2): 159-64.

[10] Shapiro R, Robinson F. The foramina of the middle fossa: a phylogenetic, anatomic and pathologic study. Am J Roentgenol Radium Ther Nucl Med. 1967; 101(4): 779-94.

[11] Kale A, Aksu F, Ozturk A, et al. Foramen of Vesalius. Saudi Med J. 2009; 30(1): 56-9.

[12] Ozer MA, Govsa F. Measurement accuracy of foramen of Vesalius for safe percutaneous techniques using computer-assisted three-dimensional landmarks. Surg Radiol Anat. 2014; 36(2): 147-54. 